\title{
Pulmonary responses to nutritional restriction and hyperoxia in premature rabbits
}

\author{
Marta M. G. B. Mataloun, ${ }^{1}$ Celso M. Rebello, ${ }^{2}$ Renata S. Mascaretti, ${ }^{3}$ \\ Marisa Dohlnikoff, ${ }^{4}$ Cléa R. Leone ${ }^{5}$
}

\begin{abstract}
Objectives: To analyze the effects of nutritional restriction and hyperoxia on lung weight and pulmonary morphometry in premature rabbits during the first 11 days of life.

Methods: New Zealand White rabbits were delivered by C-section at 28 days' gestational age and randomized into four groups: control diet and room air, control diet and hyperoxia $\left(\geq 95 \% \mathrm{O}_{2}\right)$, nutritional restriction and room air and nutritional restriction and hyperoxia $\left(\geq 95 \% \mathrm{O}_{2}\right)$. Nutritional restriction was achieved by reducing all nutrients by $30 \%$ in comparison with the control diet. Lung tissue slides were stained with hematoxylin-eosin, modified resorcin-orcein and picrosirius, before morphometric analysis was performed.

Results: From the fourth day onwards, less weight was gained by the nutritional restriction and hyperoxia group $(p<0.001)$ and from the sixth day on, by the nutritional restriction and room air group $(p<0.001)$, in comparison with their respective control groups. Nutritional restriction decreased alveoli number $(p<0.001)$ and collagen deposition $(p<0.001)$. Hyperoxia was responsible for reductions in number of alveoli $(p<0.001)$ and collagen deposition ( $p<0.001)$, in addition to higher mean linear intercept values $(p<0.05)$ and thickening of alveolar septa $(p<0.001)$. When nutritional restriction was associated with hyperoxia, the reductions in number of alveoli $(p<0.001)$ and of collagen deposition $(p<0.001)$ intensified.
\end{abstract}

Conclusions: Nutritional restriction intensified the changes of pulmonary architecture findings caused by hyperoxia, in particular through alterations to alveolarization and collagen deposition.

J Pediatr (Rio J). 2006;82(3):179-85: Nutritional restriction, hyperoxia, lung development, premature rabbits.

\section{Introduction}

Bronchopulmonary dysplasia is one of the principal causes of morbidity among preterm newborn infants, particularly the extremely premature, admitted to neonatal intensive care units. Hyperoxia, ${ }^{1}$ mechanical

1. Doutora, Unidade de Pesquisa Experimental - Pediatria Neonatal, Departamento de Pediatria, Faculdade de Medicina, Universidade de São Paulo (FMUSP), São Paulo, SP, Brasil.

2. Doutor, Unidade de Pesquisa Experimental - Pediatria Neonatal, Departamento de Pediatria, FMUSP, São Paulo, SP, Brasil.

3. Doutora, Unidade de Pesquisa Experimental - Pediatria Neonatal, Departamento de Pediatria, FMUSP, São Paulo, SP, Brasil.

4. Doutora, Departamento de Patologia, FMUSP, São Paulo, SP, Brasil.

5. Livre-docente, Professora associada, Pediatria Neonatal, Departamento de Pediatria, FMUSP, São Paulo, SP, Brasil.

Financial support: FAPESP.

Manuscript received Jul 07 2005, accepted for publication Feb 172006.

Suggested citation: Mataloun MM, Rebello CM, Mascaretti RS, Dohlnikoff $\mathrm{M}$, Leone CR. Pulmonary responses to nutritional restriction and hyperoxia in premature rabbits. J Pediatr (Rio J). 2006;82:179-85. ventilation, 2,3 perinatal infection ${ }^{4}$ and persistent ductus arteriosus 5,6 are the main risk factors, in addition to prematurity. 2,5,6 Studies are required, so that the importance of nutrition to the pathophysiology of this disorder can be understood.

Several experimental models have been used to study the acute pulmonary damage caused by hyperoxia in term animals, 1,7 in premature ones, ${ }^{8}$ during periods before or during alveolarization. Arrested alveolar and pulmonary microvascular development were the principal histopathological characteristics observed, with reduced numbers of alveoli and changes to vascular morphology. 1,7-9

The influence of nutrition upon lung development has been investigated with contradictory results. It should be pointed out that the majority of such studies have used full term or adult animals. Some studies of newborn, full term rats observed reductions in somatic growth, lung weight 
and volume, alveoli numbers and collagen content, 10,11 while others did not detect any influence from nutritional restriction on pulmonary architecture. ${ }^{12}$

An experimental model with preterm rabbits has been developed to study acute lung injury by hyperoxia and lung development. ${ }^{13-15}$ However, few experimental models of nutritional restriction and hyperoxia with premature animals have been employed, ${ }^{16}$ and, when they have been used, the impact on pulmonary architecture has not been analyzed.

A hypothesis was formulated, based on the existing published data, that nutritional restriction and hyperoxia, in isolation or associated, would have significant effects on alveolarization, interrupting alveoli formation and causing disruption of elastin fibers and collagen.

The present study was therefore designed to assess the effects of nutritional restriction and hyperoxia on the pulmonary architecture of premature rabbits in their first 11 days of life.

\section{Material and methods}

The protocol for this study was approved by the local Research Ethics Committee.

\section{Preparation of animals}

Timed-pregnant New Zealand White rabbits (Benjamin Fleder ${ }^{\circledR}$, Moji das Cruzes, SP), with gestational age 28 days, were sedated with intramuscular ketamine $(10 \mathrm{mg} / \mathrm{kg})$ and acepromazine $(0.1 \mathrm{mg} / \mathrm{kg})$ and then subjected to spinal anesthesia with marcaine-xylocaine solution at $2 \%(1: 1$, vol:vol $-2 \mathrm{ml})$. After C-section, the rabbits were identified by a number, marked on the dorsal region, and weighed over a thermal mattress and under radiant heat. They were kept with $30 \% \mathrm{O}_{2}$ during the first 30 minutes of life. The mothers were killed with pentobarbital injection $(5 \mathrm{ml})$.

After an initial adaptation period, surviving animals were randomized, by drawing lots with their numbers on, into one of the following groups: $C A$, control diet, air room ( $n=18) ; C H$, control diet, hyperoxia ( $n=17) ; R A$, nutritional restriction, air room $(n=18) ; \mathrm{RH}$, nutritional restriction, hyperoxia $(n=18)$. Subjects were killed at 11 days of life.

The animals were kept in incubators (Fanem ${ }^{\circledR}$, São Paulo, Brazil) set to maintain the temperature at 30-32 ${ }^{\circ} \mathrm{C}$. In order to prevent infections, incubators had been cleaned with nebulized distilled water, the diet was sterilized and the sawdust used to line the incubators had been autoclaved. From day three on, intramuscular crystalline penicillin $(20,000 \mathrm{UI} / \mathrm{kg})$ and streptomycin $(20 \mathrm{mg} / \mathrm{kg} / \mathrm{d})$ were given to prevent infections, which had been the principal cause of death in a pilot study undertaken to define the methodology to be employed. At the same time, vitamin $\mathrm{K}(0.002 \mathrm{mg} / \mathrm{kg} / \mathrm{day})$ was also given to prevent pulmonary hemorrhage.

A milk-based formula was developed, with a composition closer to the milk of the rabbit, ${ }^{17}$ similar to those used in earlier studies. ${ }^{13,15,18}$ The control diet was made up of a mixture of: AL110 (Nestlé ${ }^{\circledR}$ ), 5 grams; casein (Support ${ }^{\circledR}$ ), 5 grams; triglycerides CMAGE (Support ${ }^{\circledR}$ ), $15 \mathrm{ml}$; multivitamins, 1 drop; distilled water, $100 \mathrm{ml}$ qs. This diet provides 5.3 grams of proteins, 16.2 grams of fat, 2.8 grams of dextrin maltose and $155 \mathrm{kcal}$ per $100 \mathrm{ml}$. Nutritional restriction was defined as a $30 \%$ reduction in all nutrients in the control diet, based on experimental models of undernutrition. ${ }^{18}$ The ponderal evolution of rabbits in this study was the same way of the study described on literature, that used the formula ${ }^{13}$ All animals were fed twice a day by orogastric tube $4 \mathrm{Fr}$ coupled to a scaled syringe. The following volumes were given: D0, $50 \mathrm{ml} / \mathrm{kg} /$ day; D1, $100 \mathrm{ml} / \mathrm{kg} /$ day; D2, $150 \mathrm{ml} / \mathrm{kg} /$ day; D3 to D10, $200 \mathrm{ml} / \mathrm{kg} /$ day. The same volume was offered for both groups, aiming at keeping them hydrated. Latex gloves were used when handling animals and instruments.

The animals were weighed three times every morning, daily, using a precise analytic balance (TR 403, Denver Instrument Company ${ }^{\circledR}$, USA), and the arithmetic mean of measures was calculated in order to determine daily weight.

\section{Hyperoxia exposure}

Warmed and humidified oxygen was administered using neonatal nebulizers (Intermed ${ }^{\circledR}$, São Paulo, Brazil), at a $3 \mathrm{l} / \mathrm{min}$ flow rate with subjects in sealed acrylic chambers. This flow rate was sufficient to prevent $\mathrm{CO}_{2}$ accumulating and maintain a constant concentration of $95 \% \mathrm{O}_{2}$. Oxygen concentration was continuously monitored with a room air oximeter (Dixtal ${ }^{\circledR}$, São Paulo, Brazil).

\section{Histology}

Animals were killed by intraperitoneal injection of sodium pentobarbital ( $25 \mathrm{mg} / \mathrm{kg}$ ) and sectioning of the abdominal aorta. The trachea was cannulated with a 1 mm diameter Sylastic cannula. Next, bilateral pneumothorax was done by bilateral puncture of the diaphragm abdominal surface. The cannula was then connected to a water column and the lungs inflated to a pressure of $30 \mathrm{cmH} 2 \mathrm{O}$, when the trachea was ligated. The lungs were removed from the thorax and immersed in a buffered formol solution at $10 \%$ for 24 hours. After this period, the lungs were weighed three times, on TR 403 precision analytical scales (Denver Instrument Company ${ }^{\circledR}$, USA), and the arithmetic mean of the three results was taken. Lung volume was then measured by means of the water displacement. ${ }^{19}$ Measurements 
were taken three times and the arithmetic mean calculated. Measurements were taken again if any two values diverged by $0.05 \mathrm{ml}$ or more. A correction factor was not used for humid and dehydrated values because all lungs were handled identically. The lung weight/body weight ratio (LW/BW) was determined at the moment of sacrifice, and specific lung volume was determined by dividing the lung volume by $100 \mathrm{~g}$ of body weight ( $\mathrm{ml} / 100 \mathrm{~g}$ body weight). 20

Lung water content was calculated from the difference between wet and dry lung weights. The left lung was used for this, being weighed wet, and again after 72 hours at $80^{\circ} \mathrm{C} .21$ These measurements were taken using precision scales (TR403, Denver Instrument Company ${ }^{\circledR}$, USA).

Sagittal slices of tissue with $1 \mathrm{~mm}$ thickness were taken from the distal region of the upper right lobe. Tissue samples were conserved in ethylic alcohol at $70 \%$ until they were embedded in paraffin for the serial cut processing at $5 \mu \mathrm{m}$ thickness. These slices were stained with hematoxylin-eosin ( $\mathrm{HE})$, modified resorcin-orcein, for elastin fibers and picrosirius for collagen.

\section{Morphometric analysis}

The morphometric analysis was performed by the same investigator, blinded, using an optical light microscope (Nikkon E-600) with a grid (100 points/50 lines) in the eyepiece and an image analysis software (Image-Pro ${ }^{\circledR}$, Media Cybernetics INCTM, USA).

Each slide (HE, 100X) was captured through the image analysis software. Serial images from slides were captured (but not overlay parenchymal regions) with three straight lines traced in distinctive levels, from pleura to pleura, and the intercept counting of alveoli walls was proceeded. Then the intercept was calculated and divided by 2 in order to obtain the number of alveoli. The length of each straight line was measured in the image analysis software. Mean number of alveoli per slide was calculated dividing the number of alveoli by the length of the three lines. Then, the alveoli number per length unit (alveoli number $\times 10^{-3} / \mu \mathrm{m}$ ) value was obtained. 22

The mean linear intercept (MLI) was calculated for ten fields per slide $(100 \mathrm{X}) \mathrm{.}^{23}$ Fifty alveolar septa were measured per slide using the image analyzer $(400 X){ }^{24}$ The proportions of elastin fibers and collagen deposition in the pulmonary parenchyma were determined as the ratio between the number of points that coincided with stained areas and the number of points were tissues were unstained, counted in 20 fields per animal, using a counting grid with 50 lines and 100 points $(400 X){ }^{25}$ Parenchymal points were estimated by counting points that coincided with the grid as parenchymal points, with the exception of blood vessels and bronchi with diameters greater than $2 \mathrm{~mm}$.

\section{Statistical analysis}

Analysis of variance for repeated measures was employed to compare daily mean weight for each group, and multiple comparisons were made on the basis of the Wald statistic. A sample size of 17 animals was calculated in order to detect a $10 \%$ reduction in the number of alveoli, in each exposure group and the control-air groups, with an $\alpha$ of 0.05 and test power of 0.80 .

One-way analysis of variance was used to compare lung weight, volume and water content, numbers alveoli, thickness of alveolar septa, MLI and the proportions of elastin fibers and collagen. Significance was defined as $\mathrm{p}<0.05$.

\section{Results}

The mean daily weight curve demonstrates an initial reduction in weight followed by weight gain from the third day onwards, for all groups. The group that had been exposed to nutritional restriction and hyperoxia did, however, gain less weight than the control groups from the fourth day to the end of the study $(p<0.001)$ and from the sixth day on the nutritional restriction and room air group was also gaining less weight ( $p=0.001$, Figure 1 ).

\section{Pulmonary effects}

In this experimental model using premature rabbits, 11 days' nutritional restriction resulted in lower lung volume and water content $(p<0.001)$ and reductions in the number of alveoli $(p<0.001)$ and collagen deposits $(p<0.001)$.

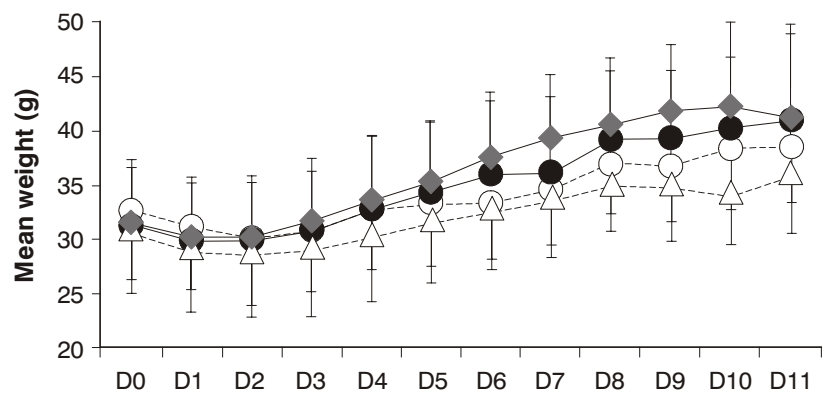

Figure 1 - Curves for mean daily weight of each over the 11 days of life

$\mathrm{CA}=$ control-air room; $\mathrm{CH}=$ control-hyperoxia; $\mathrm{RA}=$ nutritional restriction-air room; $\mathrm{RH}=$ nutritional restriction-hyperoxia.

a) $\mathrm{CA} \times \mathrm{RA}, \mathrm{p}=0.01$; b) $\mathrm{CH} \times \mathrm{RH}, \mathrm{p}<0.01$ 
Exposure to hyperoxia for 11 days also resulted in reduced numbers of alveoli $(p<0.001$ ) and collagen deposits ( $p<0.001$ ), in addition to increased septa thickness $(p<0.05)$ and MLI $(p<0.01)$.

The reductions observed in number of alveoli $(p<0.001)$ and collagen deposits $(p<0.001)$ were more intense in the group that had been exposed to both nutritional restriction and hyperoxia. Increased lung weight was also detected in this group $(p<0.001)$.

These results are described in Table 1 and Figures 2 and 3 .

\section{Discussion}

This study analyzed the effects of nutritional restriction and hyperoxia on developing immature lungs. Previous experimental models have described the repercussions of these factors, in isolation, or in the lungs of adult ${ }^{7}$ or full term newborn animals. ${ }^{1,10}$ Just a few of these demonstrated the effects of nutritional restriction and hyperoxia on premature lungs, primarily with reference to growth and antioxidant responses, after 72 hours' exposure. ${ }^{16}$ Even these models did not analyze the changes to pulmonary architecture that resulted.

The current model was chosen to make it possible to analyze the effects of nutritional restriction and hyperoxia, over 11 days, on an immature developing lung. Since gestation takes 31 days in rabbits, and because 28 days' gestational age is the limit of viability for these animals, 13 it is possible to analyze the effects of nutritional restriction and hyperoxia on lungs in the saccular phase of development, prior to alveolarization. ${ }^{15}$
The diet employed had a lower protein content than rabbit's milk has. ${ }^{17}$ Nevertheless, comparison across groups remains possible since the same source of nutrition was provided to all four groups.

The results of this study, an experimental model using premature rabbits, show that 11 days' nutritional restriction results in lower lung volume and water content, in addition to reducing the alveoli numbers and collagen deposition; hyperoxia reduces alveoli numbers and collagen deposition, concomitantly with thickening of the alveolar septa and increased MLI; in association, nutritional restriction and hyperoxia reduced alveoli numbers and collagen deposition, more intensely, and also caused increased lung weight, even after correction for total body weight.

Nutritional restriction had no observed influence on lung weight in this model, in common with an earlier study, ${ }^{16}$ although in contrast with prior expectations. When lung weight was related with to body weight the absence of influence persisted. A reduction in lung weight that was proportional to the reduced somatic weight gain would explain this unaltered observation, even without observing lower lung weight in this group than in the others. Other authors have reported lower lung weight in newborn full term rats exposed to nutritional restriction. When lung weight was corrected for somatic weight, the ratio was no different from animals given the control diet. ${ }^{10}$ The varying results observed by these studies could be the result of varying intensities of nutritional restriction. In the last study cited, nutritional restriction was not measured since it was obtained by increasing the number of animals suckling from the same mother.

Table 1 - Figures for the variables lung weight, lung weight/body weight, specific lung volume, lung water content, alveolar septum thickness, mean linear intercept, number of alveoli, collagen and elastin fiber content at 11 days

\begin{tabular}{|c|c|c|c|c|}
\hline Group & $\mathbf{C A}$ & CH & RA & $\mathbf{R H}$ \\
\hline 11 days $(n)$ & 18 & 17 & 18 & 18 \\
\hline LW $(g)$ & $0.83 \pm 0.24$ & $0.92 \pm 0.14$ & $0.76 \pm 0.14$ & $1.10 \pm 0.24 \mathrm{bd}$ \\
\hline LW/BW & $0.020 \pm 0.005$ & $0.022 \pm 0.003$ & $0.018 \pm 0.002$ & $0.029 \pm 0.006 \mathrm{bd}$ \\
\hline $\operatorname{SLV}(\mathrm{ml} / 100 \mathrm{~g})$ & $6.36 \pm 3.59$ & $4.67 \pm 1.74$ & $4.11 \pm 2.90^{a}$ & $4.25 \pm 2.48$ \\
\hline LWC & $92.85 \pm 1.30$ & $88.74 \pm 3.3$ & $79.35 \pm 5.42 \mathrm{a}$ & $78.80 \pm 5.46^{b}$ \\
\hline MLI & $60.54 \pm 18.20$ & $85.30 \pm 27.30^{c}$ & $52.70 \pm 6.50$ & $73.13 \pm 1.57^{d}$ \\
\hline Alveolar septa $(\mu \mathrm{m})$ & $5.82 \pm 1.28$ & $14.65 \pm 5.79^{c}$ & $6.38 \pm 4.04$ & $14.73 \pm 8.19^{d}$ \\
\hline Number of alveoli/mm & $0.0114 \pm 0.02$ & $0.0085 \pm 0.0012^{c}$ & $0.0076 \pm 0.001^{a}$ & $0.005 \pm 0.001 \mathrm{bd}$ \\
\hline Collagen & $0.39 \pm 0.18$ & $0.18 \pm 0.08^{c}$ & $0.13 \pm 0.05^{a}$ & $0.09 \pm 0.04$ b d \\
\hline Elastin fibers & $0.51 \pm 0.18$ & $0.40 \pm 0.20$ & $0.37 \pm 0.11^{a}$ & $0.41 \pm 0.23$ \\
\hline
\end{tabular}

$\mathrm{BW}=$ body weight $\mathrm{CA}=$ control diet and room air $\mathrm{CH}=$ control diet and hyperoxia; $\mathrm{LW}=$ lung weight; $\mathrm{LWC}=$ lung water content $\mathrm{MLI}=$ mean linear intercept; $\mathrm{RA}=$ nutritional restriction and room air; $\mathrm{RH}=$ nutritional restriction and hyperoxia; $\mathrm{SLV}=\mathrm{specific}$ lung volume.

a) $\mathrm{CA} \times \mathrm{RA}$; b) $\mathrm{CH} \times \mathrm{RH}$; c) $\mathrm{CA} \times \mathrm{CH}$; d) $\mathrm{RA} \times \mathrm{RH}$; a, b, c, d - p $<0.05$. 


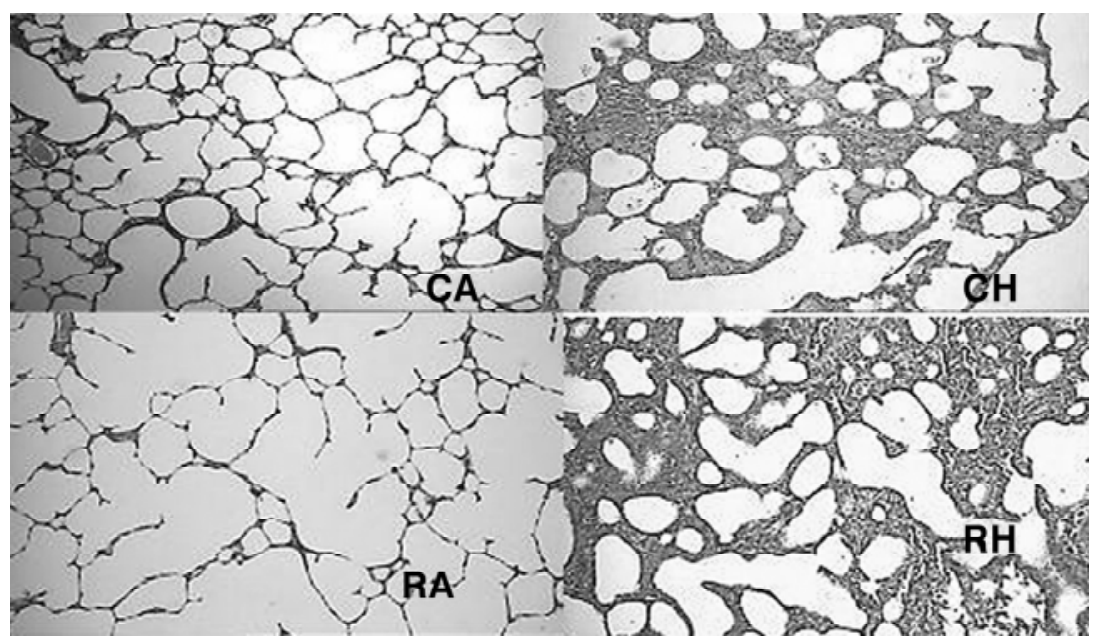

Figure 2 - Slides of premature rabbit lung - HE (X 100). A reduction in the number of alveoli is observed in the group exposed to nutritional restriction and the group exposed to hyperoxia, when compared with the group control-air room. This reduction was more intense when nutritional restriction and hyperoxia were associated. This figure also demonstrates the thickening of alveolar septa in the hyperoxia groups

$\mathrm{CA}=$ control diet and room air; $\mathrm{CH}=$ control diet and hyperoxia; $\mathrm{HE}=$ hematoxylin-eosin; $\mathrm{RA}=$ nutritional restriction and room air; $\mathrm{RH}=$ nutritional restriction and hyperoxia.

In terms of the pulmonary effects of nutritional restriction, a reduction in the number of alveoli was observed, with no alteration to alveolar dimensions, as has been described for previous models. ${ }^{26}$ These data suggest that the effect of nutritional restriction is not related to alterations to lung septation, but to another pathway involved in alveolarization.

Nutritional restriction also caused a reduction in collagen deposits in this study, in common with other researchers' descriptions, 11,27 probably due to a reduction in the availability of substrates for synthesis. Although no reduction in elastin fibers was detected, they had a coarser appearance in the group exposed to nutritional restriction. These alterations may also have been the result of lower substrate availability, interfering in the production of the enzyme lysyl-oxidase, involved in the initial stages of elastin formation, altering its appearance. $21,28,29$

In isolation, hyperoxia did not have any effect on lung weight. Earlier results on the effects of hyperoxia on lung growth are conflicting. Some studies detected increased lung weight. ${ }^{16}$ In contrast, other authors who had evaluated the effects on lung growth with newborn, full term animals described reduced lung weight and pulmonary DNA content. ${ }^{10}$ Similarly, in the current study, the increased lung water content in exposed animals described by some authors ${ }^{14}$ was not observed. These differences are probably related to the duration of exposure to hyperoxia and the degree of pulmonary immaturity.

The reduction in number of alveoli observed in animals exposed to hyperoxia, with a concomitant increase in MLI, suggests interference in alveolarization by means of inhibition of lung septation, producing larger alveoli, in agreement with other experimental models of hyperoxiainduced lung damage. ${ }^{1}$ This increase in MLI could also be a reflection of the thickening of the alveolar septa that was observed in this group, suggesting an increase of the inflammatory process. ${ }^{26}$ In this group, hyperoxia also reduced collagen deposits. Previous studies into the effects of hyperoxia on pulmonary collagen content have returned divergent results, with some detecting increased, ${ }^{1}$ and others reduced, ${ }^{20}$ deposits. This diversity may be a result of variations between models in the duration of hyperoxia or even of different animal species having varying sensitivity to hyperoxia.

The association of nutritional restriction with hyperoxia produced a more intense reduction in the number of alveoli and collagen deposits. Earlier studies have reported a reduction in DNA production in lungs both when exposed to hyperoxia and when exposed to nutritional restriction. ${ }^{10}$ It is possible that this interference with DNA could be one of the mechanisms responsible for these repercussions. 


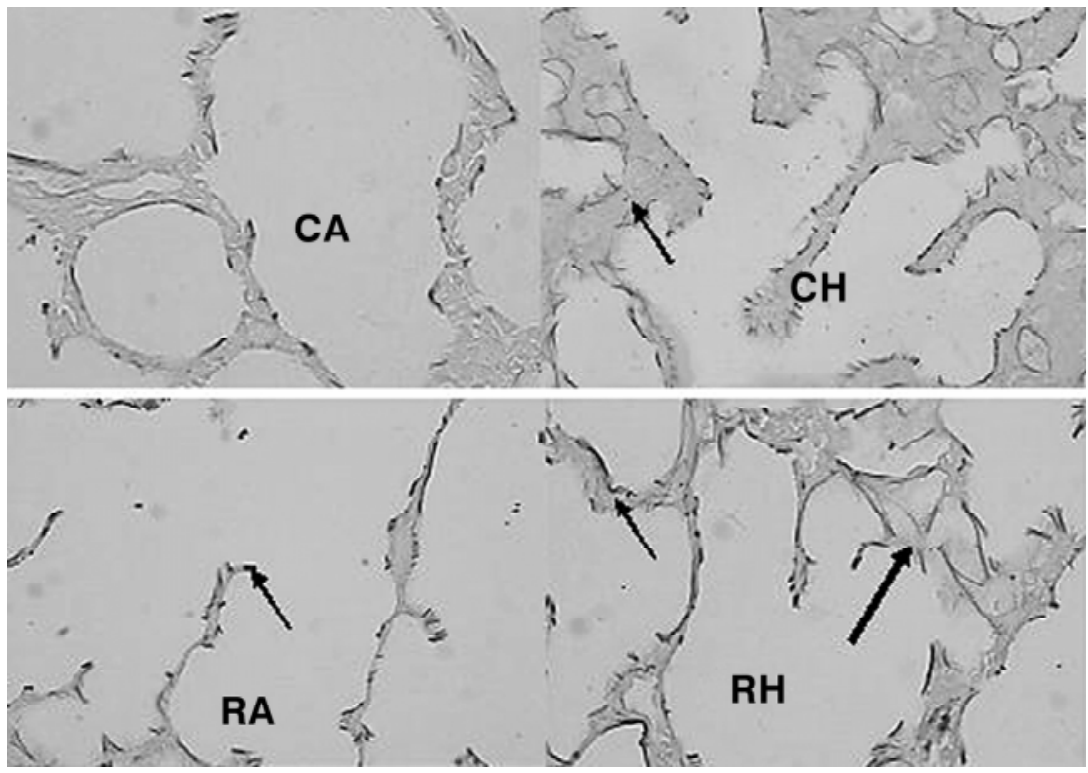

Figure 3 - Elastin fibers at 11 days - modified resorcin-orcein (X 400). Although changes to elastin fiber deposits were not detected, the elastin fibers themselves had a coarser appearance in the hyperoxia and nutritional restriction groups, and in the group that was exposed to these in association, the fibers were also deposited in an unorganized manner

$\mathrm{CA}=$ control diet and room air; $\mathrm{CH}=$ control diet and hyperoxia; $\mathrm{RA}=$ nutritional restriction and room air; $\mathrm{RH}=$ nutritional restriction and hyperoxia. a) $\mathrm{CA} \times \mathrm{RA}$; b) $\mathrm{CH} \times \mathrm{RH}$; c) $\mathrm{CA} \times \mathrm{CH}$; d) $\mathrm{RA} \times \mathrm{RH}$; a, b, c, d-p<0.001.

In this study, greater lung weight was observed when nutritional restriction and hyperoxia were associated, without, however, any increase in lung water content, as would be expected if it was associated with an inflammatory process. Other studies ${ }^{16}$ have even described reductions in this variable during exposure to these factors, relating this to a reduction in pulmonary DNA content.

The results of this study demonstrate the effects of nutritional restriction and hyperoxia on alveolarization and collagen deposition, which were more intense when the two factors were associated.

These results suggest that a reduction in the substrates necessary for tissue production could intensify the effects of hyperoxia on developing lungs, in particular with respect to alveolarization and collagen deposition. The repercussions to alveoli and MLI that were detected suggest that these factors may also arrested (or inhibition) alveolarization, by different means, causing an intensified effect.

Components of the extracellular matrix, including collagen, growth factors, humoral factors and, primarily, elastin, are involved in regulating alveolarization. 29,30 A deficiency of substrates could be responsible for reduced availability of these factors and, therefore, involved in these effects.

In this study, an arrested alveolarization was observed, produced by early postnatal nutritional restriction and hyperoxia, which is one of the principal histopathological observations in "new" bronchopulmonary dysplasia. This being so, it is possible that early neonatal nutrition could have a modulatory role in the pulmonary injuries caused by hyperoxia.

\section{References}

1. Warner BB, Stuart LA, Papes RA, Wispe JR. Functional and pathological effects of prolonged hyperoxia in neonatal mice. Am J Physiol. 1998;275:L110-7.

2. Coalson JJ, Winter VT, Siler-Khodr T, Yoder BA. Neonatal chronic lung disease in extremely immature baboons. Am J Respir Crit Care Med. 1999;160:1333-46.

3. Mataloun MMGB, Leone CR, Ono NA, Prado PP, Britto MGS, Vaz FAC. Risk factors of bronchopulmonary dysplasia in very low birth weight infants. Pediatr Res. 2005;57:2066A.

4. Jobe $\mathrm{AH}$. Antenatal associations with lung maturation and infection. J Perinatol. 2005;25(Suppl 2):S31-5.

5. Monte VLF, Silva Fo LVFS, Miyoshi MH, Rozov T. Displasia broncopulmonar. J Pediatr (Rio J). 2005;81:99-110. 
6. D'Angio CT, Maniscalco WM. Bronchopulmonary dysplasia in preterm infants: pathophysiology and management strategies. Paediatr Drugs. 2004;6:303-30.

7. Crapo JD. Morphologic changes in pulmonary oxygen toxicity. Annu Rev Physiol. 1986;48:721-31.

8. Tanswell AK, Wong L, Possmayer F, Freeman BA. The preterm rat: a model for studies of acute and chronic neonatal lung disease. Pediatr Res. 1989;25:525-9.

9. Lin YJ, Markham NE, Balasubramaniam V, Tang JR, Maxey A, Kinsella JP, et al. Inhaled nitric oxide enhances distal lung growth after exposure to hyperoxia in neonatal rats. Pediatr Res. 2005;58:22-9.

10. Frank L, Groseclose E. Oxygen toxicity in newborn rats: the adverse effects of undernutrition. J Appl Physiol. 1982;53: 1248-55.

11. Das RM. The effects of intermittent starvation on lung development in suckling rats. Am J Pathol. 1984;117:326-32.

12. Kalenga M, Tschanz AS, Burri PH. Protein deficiency and the growing rat lung. II. Morphometric analysis and morphology. Pediatr Res. 1995;37:789-95.

13. Lorenzo AV. The preterm rabbit: a model for the study of acute and chronic effects of premature birth. Pediatr Res. 1985;19: 201-5.

14. Johnsson H, Eriksson L, Jonzon A, Laurent TC, Sedin G. Lung hyaluronan and water content in preterm and term rabbit pups exposed to oxygen or air. Pediatr Res. 1998;44:716-22.

15. Kovar J, Sly PD, Willet KE. Postnatal alveolar development of the rabbit. J Appl Physiol. 2002;93:629-35.

16. Langley SC, Kelly FJ. Effect of food restriction on hyperoxiainduced lung injury in preterm guinea pig. Am J Physiol. 1992;263: L357-62.

17. Sogorb F, Damy SB, Rodrigues UP, Chaguri ICAG. Variação na composição do leite de coelha. Mem Inst Butantan. 1991;53: 175-80.

18 Kerr JS, Riley DJ, Lanza-Jacoby S, Berg RA, Spilker HC, Yu SY, et al. Nutritional emphysema in the rat. Am Rev Respir Dis. 1985; 131:644-50.

19. Scherle W. A simple method for volumetry of organs in quantitative Stereology. Mikroskopie. 1970;26:57-60.
20. Bruce MC, Bruce EN, Janiga K, Chetty A. Hyperoxic exposure of developing rat lung decreases tropoelastin mRNA levels that rebound postexposure. Am J Physiol. 1993;265:L293-300.

21. Chen Y, Martinez MA, Frank L. Prenatal dexamethasone administration to premature rats exposed to prolonged hyperoxia: a new rat model of pulmonary fibrosis (bronchopulmonary dysplasia). J Pediatr. 1997;130:409-16.

22. Dunnil MS. Quantitative methods in the study of pulmonary pathology. Thorax. 1962;17:320-8.

23. Thurlbeck WM. The internal surface area of nonemphysematous lungs. Am Rev Respir Dis. 1967;95:765-73.

24. Stocker JT. Pathologic features of long-standing "healed" bronchopulmonary dysplasia: a study of 28 3- to 40-month-old infants. Hum Pathol. 1986;17:943-61.

25. Dolhnikoff M, Mauad T, Ludwig MS. Extracellular matrix and oscillatory mechanics of rat lung parenchyma in bleomycin induced fibrosis. Am J Respir Crit Care Med. 1999;160:1750-7.

26. Massaro D, Teich N, Maxwell S, Massaro GD, Whitney $P$. Postnatal development of alveoli: regulation and evidence for a critical period in rats. J Clin Invest. 1985;76:1297-305.

27. Kalenga $M$, Eeckout $Y$. Effects of protein deprivation from the neonatal period on lung collagen and elastin in the rat. Pediatr Res. $1989 ; 26: 125-7$

28. Tinker D, Rucker RB. Role of selected nutrients in synthesis, accumulation and chemical modification of connective tissue proteins. Physiol Rev. 1985;65:607-57.

29. Bourbon J, Boucherat O, Chaileey-Heu B, Delacourt C. Control mechanisms of lung alveolar development and their disorders in bronchopulmonary dysplasia. Pediatr Res. 2005;57:38R-46R.

30. Ambalavanan N, Carlo WA. Bronchopulmonary dysplasia: new insights. Clin Perinatol. 2004;31:613-28.

\section{Correspondence:}

Marta M. G. B. Mataloun

Rua Antônio Júlio dos Santos, 524/33

CEP 05661-020 - São Paulo, SP - Brazil

Tel.: + 55 (11) 3742.1042

E-mail: mataloun@uol.com.br 